\title{
What do mothers remember about the 'Back to Sleep' campaign?
}

\author{
C M H Hiley, C Morley
}

\begin{abstract}
A campaign was launched by the Department of Health late in 1991 to advise mothers how to reduce the risk of cot death.

Objective-To investigate whether mothers remember receiving this advice, their sources of information, and the advice they were given.

Setting-Questionnaires filled in by mothers of babies born in three maternity units in East Anglia.

Method-450 mothers of full term babies born throughout 1992 were enrolled. All of them should have received the information. They were sent a questionnaire when their baby was 6 months old.

Results-399 (89\%) questionnaires were analysable. Sources of information were: television, 72\%; magazines, 59\%; midwives, $55 \%$; health visitors, $48 \%$; and doctors, $11 \% .23 \%$ said they received no advice from a health professional about reducing the risk of cot death. Doctors, who had all been informed by the Department of Health, were surprisingly poor at passing on the information. Advice on sleeping position was remembered by $72 \%$, overheating by $60 \%$, and smoking by $35 \%$. Problems in following the advice were reported by only $5 \%$ of mothers.

Conclusions-The media was most influential in spreading the new advice. Basic infant care advice is not the preserve of doctors.

(Arch Dis Child 1995; 73: 496-497)
\end{abstract}

Keywords: cot death, mothers, advice, infant care.

The 'Back to Sleep' campaign to reduce the risk of cot death was launched nationally in December 1991. There was a two week television advertising campaign, a leaflet available for mothers, and a letter was sent to all doctors and nursing officers. There was little prior information for health professionals for this change in advice.

The study had three aims: to quantify mothers' sources of information about reducing the risk of cot death, to identify what information mothers remembered receiving, and to determine whether mothers were having any problems following the advice.

\section{Methods}

This is part of a large study investigating infant care before and after the Back to Sleep campaign. One hundred and fifty mothers of full term babies born between 1 January and 31 December 1992 were enrolled from each of the maternity units in Cambridge, Huntington, and Bury St Edmunds. They should have received information about reducing the risk of cot death. Mothers of infants who had been in a neonatal unit or who had major congenital abnormalities were excluded. Equal numbers were chosen for each month of the year. Random number tables were used to select the dates of the month and then the number of the birth on that day. If the baby had to be excluded the next appropriate numbers from the tables were used to select another baby.

The project was approved by all three district ethics committees. Mothers knew that they were involved in a study related to cot death. To maximise the response all the envelopes and letters were hand addressed and stamped and it was identified as a local research programme. A questionnaire was sent when the baby was 6 months old.

\section{Results}

Three hundred and ninety nine (89\%) questionnaires were returned and suitable for analysis. Mothers' ages ranged from 17 to 44 years with a mean of 28.5 years. One hundred and eighty two mothers $(46 \%)$ were primigravidas. The educational level was: 151 $(38 \%)$ finished school at 16 years, $145(36 \%)$ underwent vocational training, 53 (13\%) had professional training, and $48(12 \%)$ were graduates.

The figure shows the response to the question, 'Have you had advice about reducing the risk of cot death from any of the following?' Many mothers had information from more than one source. To investigate whether the information mothers remember receiving changed with time the answers were also compared for the first and last quarters of the year; no significant difference was found.

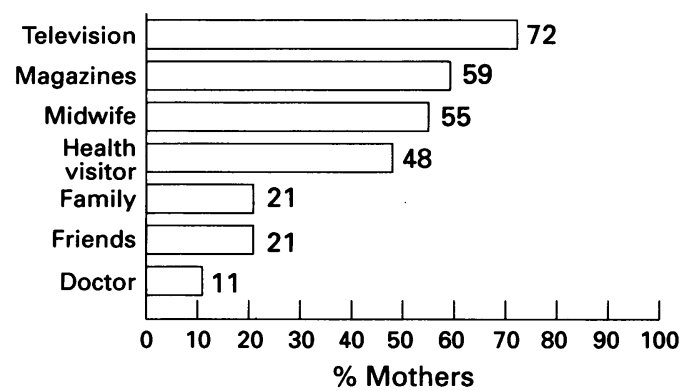

Percentage of mothers citing different sources of information. 
We did not differentiate between the leaflets from the Foundation for the Study of Infant Deaths and those published by the Department of Health. The distribution of the Back to Sleep leaflets was patchy: $1 \%$ of mothers reported receiving leaflets from their doctor, $12 \%$ from a health visitor, $10 \%$ from a midwife, $1 \%$ via television advertisements, and $3 \%$ from magazine information.

Information on the increased risk of cot death if mothers smoke was reported by to have been received from doctors $(2 \%)$, health visitors $(11 \%)$, midwives $(14 \%)$, television $(32 \%)$, and from magazines $(35 \%)$.

The dangers of overheating babies was reported to have been received from $4 \%$ of doctors, $52 \%$ of health visitors, $48 \%$ of midwives, from the television by $50 \%$, and magazines by $60 \%$.

The importance of not sleeping babies on their front was reported to have been given by their doctors to $6 \%$ of mothers, by health visitors to $62 \%$, by midwives to $67 \%$, from the television by $69 \%$, and from magazines by $72 \%$.

Some mothers criticised the availability of the information: 12 (3\%) claimed they received no information, $36(9 \%)$ had not seen the information on television or in magazines, and $91(23 \%)$ had not received any information from a health professional. About a third, $124(31 \%)$, were pleased with the advice they received. The rest of the comments were either non-committal or could not be analysed.

A few mothers, 20 (5\%), had problems following the advice on sleeping position. Most were due to the babies not settling on their backs or sides. The advice on smoking caused problems for $12(3 \%)$ mothers because they could not give up or their friends and relatives smoked near the baby. Problems with heating or clothing were experienced by $28(7 \%)$ who found the balance between heat and cold difficult to maintain.

Although not part of the advice in the campaign, about $5 \%$ of mothers reported they had received information on breast feeding and about $1 \%$ about mattresses. Television and magazines were again reported as the main sources.

\section{Discussion}

This study only presents data on what mothers remember about the information they received. It is possible they received information but had forgotten about it.

The most memorable information and therefore the most successful was obtained from television and magazines. Although television advertising is the most expensive method it had advantages over the other methods. It disseminates information to the whole of society and ensures that mothers are informed both directly and indirectly. The lack of difference in sources of information between the first and last quarters of 1992 suggests that the media campaign was so successful that the advice was remembered even though the television advertisements had not been shown for nine months. This emphasises the strength of the media information.

Surprisingly, only about half the mothers remember receiving information from health visitors and midwives, whose role is to advise about the care of babies. If this is true, health authorities need to ensure that they inform all mothers about factors which reduce the risk of cot death.

Doctors, who were given the most information by the Department of Health, ${ }^{1}$ were the worst at informing their patients. They were less significant sources of information than even friends and relatives. This has implications for the way future campaigns should be run. Instead of giving the majority of information to the doctors, the data suggest that the most effective means of disseminating the information is via the media, health visitors, and midwives. The main advantage health professionals have over the media is the chance of discussing the advice with mothers. Sadly, $23 \%$ of the mothers in the study do not remember being given this opportunity.

Over twice the number of mothers remember receiving information about the dangers of smoking from the media than from the most effective health professional, the midwife. Similarly, although the promotion of breast feeding in relation to cot death is not part of the current advice the media were four times more effective in promoting it than were health professionals.

Surprisingly, few mothers reported problems with following the advice they received.

Even though the recent fall in the incidence of cot death may be in part due to the campaign to inform mothers about the risk factors for cot death, the data in this study suggest that there is no room for complacency. The target should be that everybody, not just mothers, are fully informed about the dangers of smoking, overwrapping, and sleeping prone. The media appear to be the most effective way of doing this. If all parents were properly informed about how to reduce the risk of cot death the rate should continue to fall from being one of the commonest causes of death in infancy to one of the rarest. The momentum of the campaign must not be lost. The message is that television and magazines are the most effective means of spreading the word.

Mrs Hiley is grateful for financial support from the Foundation for the Study of Infant Deaths, the University of Cambridge Baby Research Fund, and the Oxford and Anglia Regional Health Authority Audit Committee. We also thank the mothers for filling in our questionnaires when they were so busy.

1 Department of Health. Sleeping position of infants and the risk of cot death (sudden infant death). London: Department of PL(CNO)(91)11.) 